\title{
RECFIVED
}

\author{
JUL 291997
}

OSTI

\section{A DESCRIPTION OF A WIDE BEAM SADDLE FIELD ION SOURCE USED FOR NUCLEAR TARGET APPLICATIONS}

\author{
John P. Greene, Stacey L. Schiel, and George E. Thomas Physics Division, \\ Argonne National Laboratory, \\ 9700 South Cass Avenue, Argonne, IL 60439, USA
}

\begin{abstract}
A description is given of a new, wide beam saddle field sputter source used for the preparation of targets applied in nuclear physics experiments. The. ion source characteristics are presented and compared with published results obtained with other sources. Deposition rates acquired utilizing this source are given for a variety of target materials encountered in nuclear target production. New applications involving target thinning and ion milling are discussed.
\end{abstract}

\section{DISCLAIMER}

This report was prepared as an account of work sponsored by an agency of the United States Government. Neither the United States Government nor any agency thereof, nor any of their employees, makes any warranty, express or implied, or assumes any legal liability or responsibility for the accuracy, completeness, or usefulness of any information, apparatus, product, or process disclosed, or represents that its use would not infringe privately owned rights. Reference herein to any specific commercial product, process, or service by trade name, trademark, manufacturer, or otherwise does not necessarily constitute or imply its endorsement, recommendation, or favoring by the United States Government or any agency thereof. The views and opinions of authors expressed herein do not necessarily state or reflect those of the United States Government or any agency thereof. 


\section{DISCLANMER}

Portions of this document may be illegible in electronic image products. Images are produced from the best available original document. 


\section{Introduction}

The usefulness of sputtering as a method for the deposition of thin films used in nuclear target development is well established. The early use of small, inexpensive saddle field ion sources employed for sputtering has been described previously $[1,2,3]$. We present here a description of a new, compact wide beam saddle field sputter gun which can be utilized for the production of the targets needed for nuclear physics experiments. This wide beam sputter source is particularly suited to recent efforts involving target thinning and ion etching. Studies involving deposition rates obtained using this source with various materials will be given and compared with results obtained with fine beam saddle field sources being carried out at other target laboratories [4].

\section{Description of the Wide Beam Saddle Field Ion Source}

The principle of operation of saddle field ion sputtering is the cold cathode discharge of inert (or reactive) gas at low pressure $\left(5-8 \times 10^{-4}\right.$ torr) without the need for a magnetic field. When a high voltage discharge occurs through this gas, a plasma is created. The plasma is confined within the source by an electric field, which is formed symmetrically about the specially shaped central anode. The source is designed to operate at levels up to $10 \mathrm{kV}$ with beam currents as high as $250 \mathrm{uA}$. A standard, constant voltage power supply Model B50, obtained from Ion Tech [5], is employed to provide power for the saddle field ion source.

We have purchased a Model B21bW [6] wide beam sputter gun from the VCR Group [7]. A photograph of this sputter source is given in Figure 1. The compact size of this source is virtually identical to the Model B11 fine beam saddle field ion source presently used in our target laboratory [8]. The type shown is the water-cooled version which allows for reduced heat radiated to the target and substrate under extended operation. Figure 2 gives the overall dimensions of the wide beam sputter gun.

The source is mounted in an aluminum holder positioned at an angle of 30 degrees with respect to the plane of the sputtering target. The angle was chosen on $r=c o m m e n d a t i o n s$ from the supplier and based upon previous work with saddile-field sources for the production of nuclear targets $[1,3,4]$. Although the yield will vary with incident angle of the sputtering ion, no attempt has been made to investigate maximum yield vs. angle of incidence for this source. 
The source is adjustable in distance from the sputter target along aluminum rails maintaining this angle. Under normal operation the source to target distance is approximately $5 \mathrm{~cm}$. The substrate, a backing foil mounted on a standard ATLAS target frame, is positioned $2 \mathrm{~cm}$ above the sputter target. Although the angular distribution of the sputtered material may vary considerably based on the energy of the sputtered beam as well as the material being sputtered, no effort was made to position the substrate so as to maximize collection of the sputtered material. For the determination of the deposition rate, a small, carefully weighed glass disk is used as the substrate. A photograph of this sputtering arrangement is shown in Figure 3. An attractive feature of this inexpensive set-up is that it is mounted completely on a vacuum feed-thru ring which is incorporated into the vacuum evaporator for use and removed when no longer needed.

\section{Operational Characteristics}

In most respects this wide beam source is identical to the fine beam sputter source, the major difference being the larger beam aperture. The source specifications given by the manufacturer are for $5 \mathrm{kV}$ operation with a plasma or source current of $2 \mathrm{~mA}$. Under these conditions, the ion current obtained is about 100 uA with a gas pressure of $5 \times 10^{-4}$ torr and $150 \mathrm{~V} / \mathrm{sec}$ pumping speed. The operational characteristics, however, vary considerably and will be discussed in detail.

\subsection{Beam Spot Size}

The main motivation behind developing this source technology in the target laboratory is to build upon previous research with thinning foils by ion beam sputtering [9]. A schematical representation of this ion milling process is shown in Figure 4. The B21bW wide beam ion source produces a beam approximately $1 \mathrm{~cm}$ long and diverging at an angle of 15 degrees with respect to the beam axis. Due to limitations imposed by the water cooling lines, the source is mounted with the long axis of the aperture positioned vertically with respect to the sputter target. This limitation has not proved adverse and can be corrected by a redesign of the aluminum holder arrangement. The beam spot obtained with this set-up shows sputtering from the target area of approximately $29 \mathrm{~mm} \times 10 \mathrm{rm}$ in size. The cperating parameters for the source using argon gas were $8 \mathrm{kV}$ applied voltage and plasma current of $2 \mathrm{~mA}$ giving a average beam currert of 50 UA. The partial pressure of argon was approximately $1.8 \mathrm{x}$ $10^{-5}$ torr.

An aralysis of the ion beam spot size under these conditions, using thin gold and nickel films reveals a somewhat gaussian shaped intensity distribution with the highest intensity contained within the central $2 \mathrm{~mm}$ of the beam. A scan of the beam profile is obtained using the film thickness of the sputtered foil 
determined by alpha particle energy loss measurements. These scans are shown for foils of original thickness before sputtering of $3 \mathrm{mg} / \mathrm{cm}^{2}$ for Au (Fig. 5) and $\mathrm{Ni}$ (Fig. 6), respectively.

\subsection{Gas Handling}

The sputter source is operated within a vacuum chamber employing a CTI Model CryoTorr-8 cryopump with a pumping speed of $1500 \mathrm{l} / \mathrm{sec}$ for nitrogen. This is an order of magnitude better than that specified in the product literature [6]. We find satisfactory operation of the source with a system pressure of $5-8 \times 10^{-5}$ torr, again an order of magnitude different than the manufacturer's specifications [6]. Due primarily to the increased pumping speed, the ultimate vacuum improves during initial operation of the source. This then requires periodic gas flow adjustments which is reflected in the measured beam current.

Although we have begun preliminary investigations involving reactive gases the research described here concentrates on use of the noble gases. For the sputter yield studies, a partial pressure of $1-2 \times 10^{-5}$ torr of argon was used. Similar conditions were required for ion milling operations using krypton.

\subsection{Beam Current Measurements}

The symmetrical geometry of the saddle field source also produces a rear directed beam which is collected by the monitor plate. This aluminum monitor plate is connected to an ion current monitor with the beam current displayed on the power supply panel. Only a small part of the beam is collected on the monitor plate, as the beam exits through the $1.5 \mathrm{~mm}$ diameter rear cathode. The ratio of the geometrical areas of the front to rear cathodes is approximately ten. In addition, only a fraction of the true beam intensity is reflected by the ion current monitor since the neutral content of the beam is not measured. For ion milling applications, the total beam intensity (ions+neutrals) must be taken into account as the momentum of the neutrals is similar to that of the ions and provide a substantifil contribution to the sputtering yield as determined from etching rate metsurements [8]. From data published for the fine beam saddle field ion sourc extrapolated to these operating levels, the neutral component of the beam 3 estimated to be approximately $20 \%$ of the total beam intensity.

Normal operating parameters for the wide beam source used an accelerating potential of $8 \mathrm{kV}$ with a plasma current of $2 \mathrm{~mA}$. Under these conditions, ion currents of about 40 uA were achieved. Figure 7 shows plots of ion current vs. accelerating voltage for several plasma currents obtained using this wide beam source. 


\section{Experimental Results and Applications}

Aiter establishing reliable operation of the source using our set-up, a series of measurements were made for comparison with those provided by the manufacturer. A systematic study was then undertaken to determine deposition rates for a variety of materials common to nuclear target production. Applications involving ion milling were also investigated and a series of measurements performed.

\subsection{Sputter Deposition Rates and Ion Milling Rates}

Results are presented here from an investigation of deposition rates obtained using this wide beam ion source having argon as the sputtering gas for a variety of materials. The operating parameters of the source for this study

were $8 \mathrm{kV}$ accelerating potential, a partial pressure of argon of $1-2 \times 10^{-5} \mathrm{torr}$, and a plasma current of $2 \mathrm{~mA}$. The beam currents measured varied between 45 and 50 uA averaged over the 1 hour duration of the deposition. Table I gives these sputtering rates and compares them with data previously published by the manufacturer of this ion source [10]. As the sputtering conditions vary considerably, these rates have been normalized to the rate obtained for copper. The results obtained are, in some instances, substantially greater for this wide beam source.

As the main purpose intended for this source was for ion milling and etching applications, a series of rate measurements were performed, this time employing krypton in the ion source. Table II shows the results of these measurements for a variety of materials. The source was operated at $8 \mathrm{kV}$ applied voltage and $2 \mathrm{~mA}$ plasma current. The partial pressure of krypton was $1-2 \times 10^{-5}$ torr. Beam currents obtained using krypton averaged closer to $40 \mathrm{uA}$ as compared with 45-50 uA obtained using argon. The estimated erosion, or ion milling rate is based on the material consumption obtained using the deposition rate measured, determined by careful weighing of the glass substrate, and the geometry of the set-up. For this purpose, the angular distribution of the sputtered material is assumed to be cosinusoidal.

This assumption is not without merit as earlier studies have shown, and is based upon ine calculations of Maier [4]. A more precise determination of the erosion couis be obtained by accurately weighing the sputtered target foil before and aiter the milling process, thus measuring the amount of material ejected. Th statistical uncertainties in these measurements is not easy to establish. th e main errors encountered being the precise duration time and the dificulties a: :sing from weighing microgram quantities. For the results presented r.ere, several measurements were made. The deposition rates observed compare favorably with published data available from other laboratories using the fine beam saddle field source (see for example Ref. [11]). 


\subsection{Other Applications}

Besides the ion milling applications already discussed for the thinning of target foils beyond that achieved by mechanical rolling, a number of other

applications are under investigation. This wide beam source has been used for the removal of oxide layers from targets, making them available for reuse. This method was recently employed for $\mathrm{Pb}$ stopper foils for experiments at GAMMASPHERE. Another application being explored involves ion cleaning of carbon deposits from foils that have been irradiated by heavy-ion beams. Future efforts will be to investigate substrate surface preparation for enhanced bonding of target materials during deposition.

\section{Conclusions}

In conclusion, this wide beam saddle field ion source affords us a valuable new technique for nuclear target development and should find widespread use within the target community. It complements the use of the fine beam source already established in applications involving large sputtering areas such as for ion milling and etching.

\section{Acknowledgements}

The authors would like to thank Dr. Walter Henning, the Physics Division Director, and Dr. Irshad Ahmad, the Target Facility Group Leader, for their continuing encouragement and support of these efforts. We would also like to thank Vince Carlino of the VCR Group for his help in solving problems associated with the operation of this sputter gun. This work is supported by the U.S. Department of Energy, Nuclear Physics Division, under Contract No. W-31-109-Eng-38. 


\section{References}

[1] R.J. Drinkwater, Proc. 11th World Conference of the International Nuclear Target Development Society, Seattle, WA, USA, 1982, p. 217.

[2] G.E. Thomas, Proc. Workshop of the Intemational Nuclear Target Development Society, 1983 ANL/PHY-84-2, p. 249.

[3] A.H.F. Muggleton, Nucl instr. and Meth. A303 (1991) 157.

[4] H.J. Maier, Nucl instr. and Meth. A303 (1991) 172.

[5] Ion Tech Ltd. 2 Park Street, Teddington, Middlesex, TW11 OLT, England

[6] B21 WIDE BEAM SADDLE FIELD ION SOURCE, Information Sheet C, Ion Tech Ltd. 2 Park Street, Teddington, Middlesex, TW11 OLT, England

[7] VCR Group, 250 East Grand Avenue, Suite 31, South San Francisco, CA, 94080.

[8] B11 FINE BEAM SADDLE FIELD ION SOURCE, Information Sheet B, Ion Tech Ltd. 2 Park Street, Teddington, Middlesex, TW11 OLT, England

[9] G.E. Thomas and J.P. Greene, Nucl Instr. and Meth. A334 (1993) 132136

[10] "Ion Beam Micro-Sputtering of Thin Films", Ion Tech Ltd. 2 Park Street, Teddington, Middlesex, TW11 OLT, England

[11] H.J. Maier, Nucl Instr. and Meth. A334 (1993) 137. 
Tables

Table I - Table of Ion Beam Sputtering Deposition Rates using Argon

Table II - Deposition Rates and Estimated Erosion Based on Consumption Rates for Various Materials using Krypton

\section{Figure Captions}

Figure 1. Photograph showing the B21bW Wide Beam Saddle Field Ion Source

Figure 2. Drawing of the B21bW Wide Beam Saddle Field Ion Source

Figure 3. Schematic Representation of the lon Milling Process

Figure 4. Photograph showing the sputtering set-up.

Figure 5. Beam profile scan from film thickness measurements of a sputtered $3 \mathrm{mg} / \mathrm{cm}^{2}$ Au foil as determined by alpha particle energy loss measurements.

Figure 6. Beam profile scan from film thickness measurements of a sputtered $3 \mathrm{mg} / \mathrm{cm}^{2} \mathrm{Ni}$ foil as determined by alpha particle energy loss measurements.

Figure 7. Plot of lon Current vs. Accelerating Voltage for a variety of Plasma Currents 
Table I

(for Argon)

Element

Depositiona)

Rate

(Å/minutes)

Our

Results

(Ả/minutes)

\begin{tabular}{lrr}
\hline Copper & 100 & 100 \\
Aluminum & 49 & 54 \\
Silicon & 35 & - \\
Titanium & 21 & 50 \\
Chromium & 26 & 86 \\
Iron & 37 & 43 \\
Nickel & 59 & 109 \\
Germanium & 51 & - \\
Molybdenum & 39 & 47 \\
Silver & 170 & 175 \\
Tungsten & 30 & 36 \\
Platinum & 138 & 73 \\
\hline
\end{tabular}

a)from Ref. [10]. 
Table II

(for Krypton)

Target Foil

$\mathrm{Mg}$

$27 \mathrm{Al}$

$\mathrm{Ti}$

$\mathrm{Cr}$

$\mathrm{Fe}$

$\mathrm{Ni}$

$\mathrm{Cu}$

$\mathrm{Zn}$

Mo

$\mathrm{Ag}$

Sn

W

$\mathrm{Pt}$

${ }^{197} \mathrm{Au}$

$\mathrm{Pb}$

${ }^{209} \mathrm{Bi}$
Deposition

Rate

$\left(\mu \mathrm{g} / \mathrm{cm}^{2} / \mathrm{hr}\right)$
Estimated Erosion Based on Consumption Rate ( $\mathrm{mg} / \mathrm{hr}$ )

$\begin{array}{rr}1.4 & .02 \\ 29.5 & .37 \\ 25.3 & .32 \\ 28.1 & .35 \\ 47.7 & .60 \\ 71.5 & .90 \\ 71.5 & .90 \\ 109.4 & 1.37 \\ 222 & 2.79 \\ 58.9 & .74 \\ 230 & 2.89 \\ 162.7 & 2.04 \\ 110 & 1.38 \\ 192 & 2.41 \\ 236 & 2.97 \\ 311 & 3.91 \\ 321 & 4.03\end{array}$

.02

32

.35

.60

90

1.37

.79

.74

2.89

1.38

2.41

2.97

4.03 


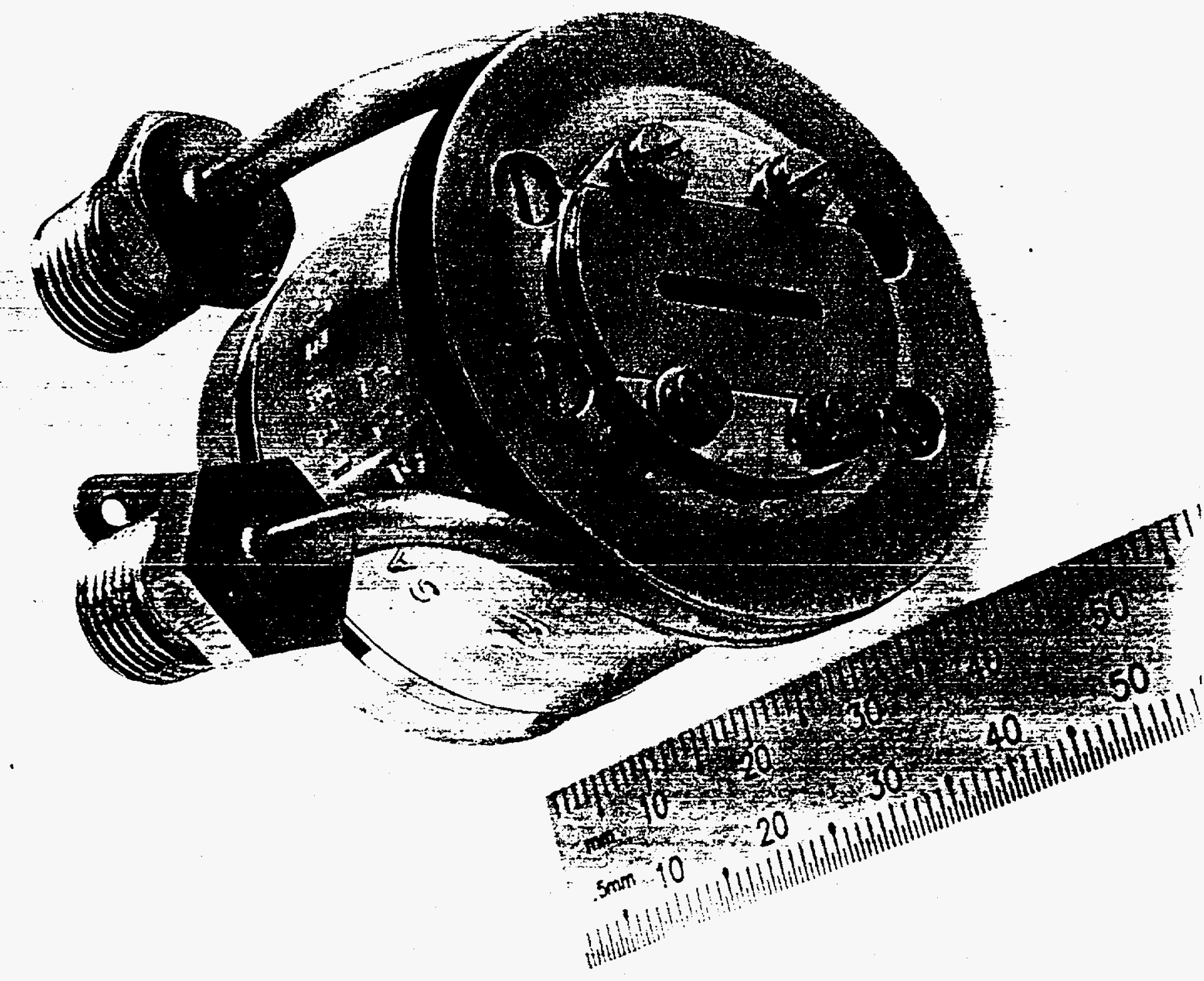




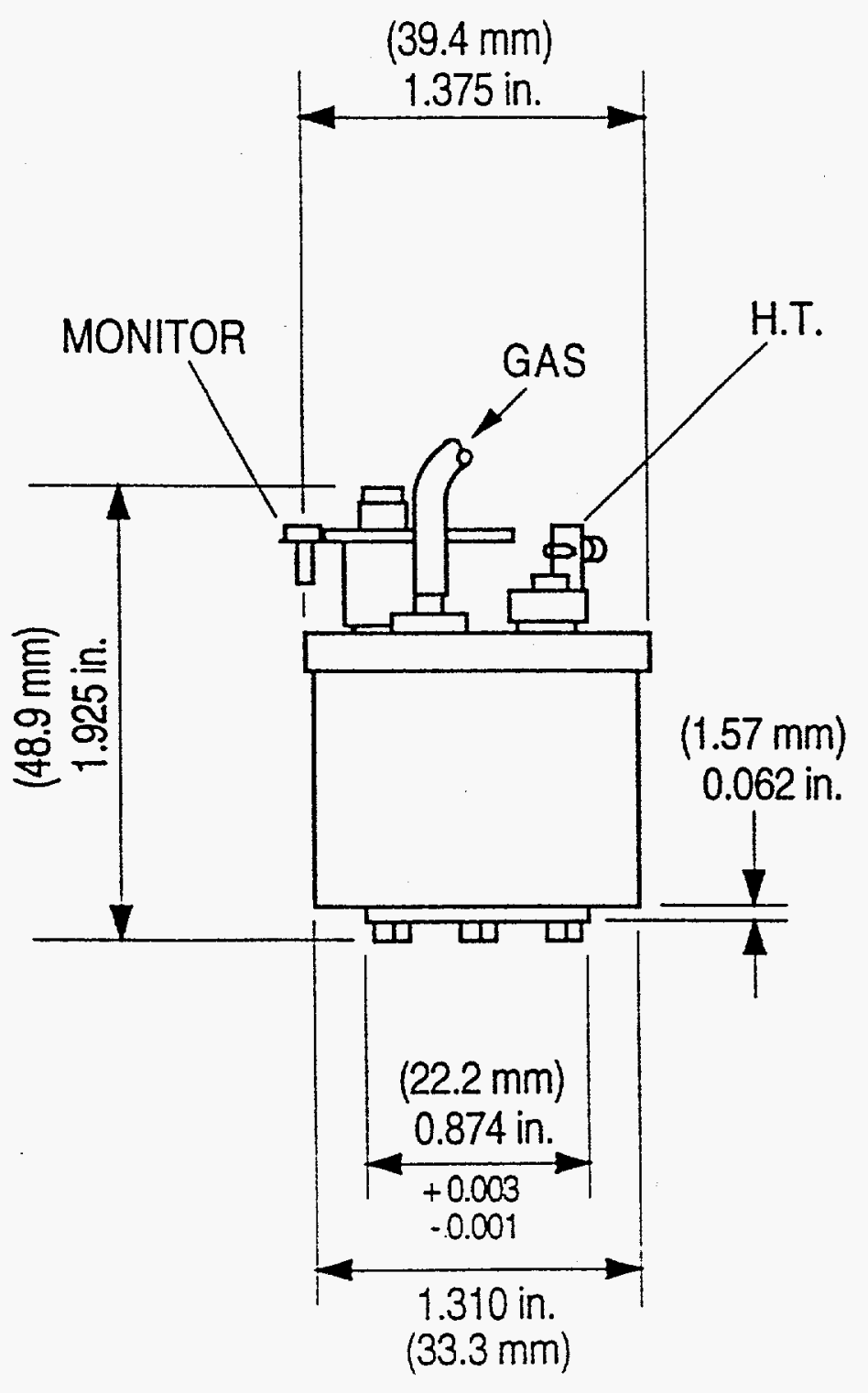

Fig. 2 


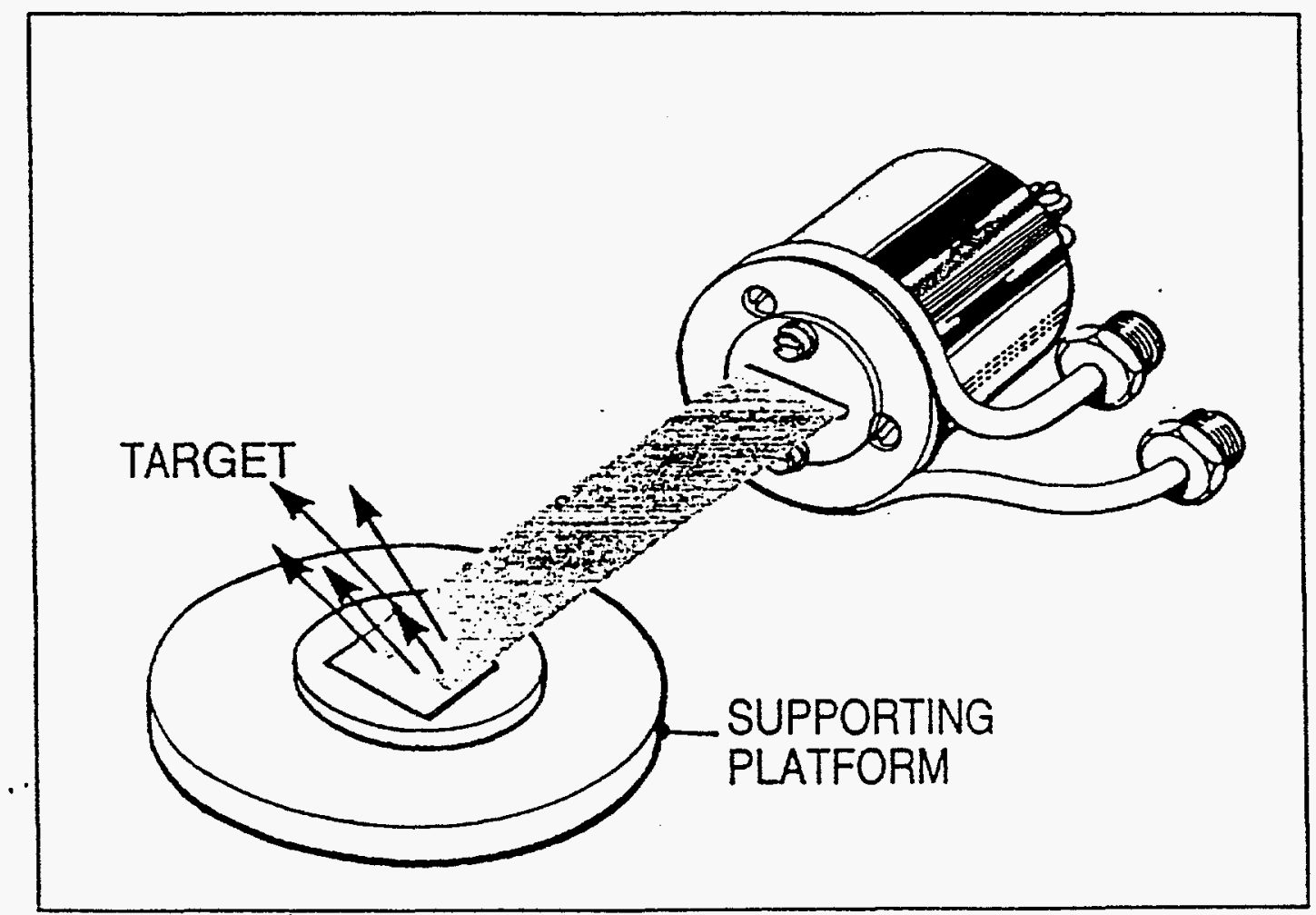

Fig. 3 


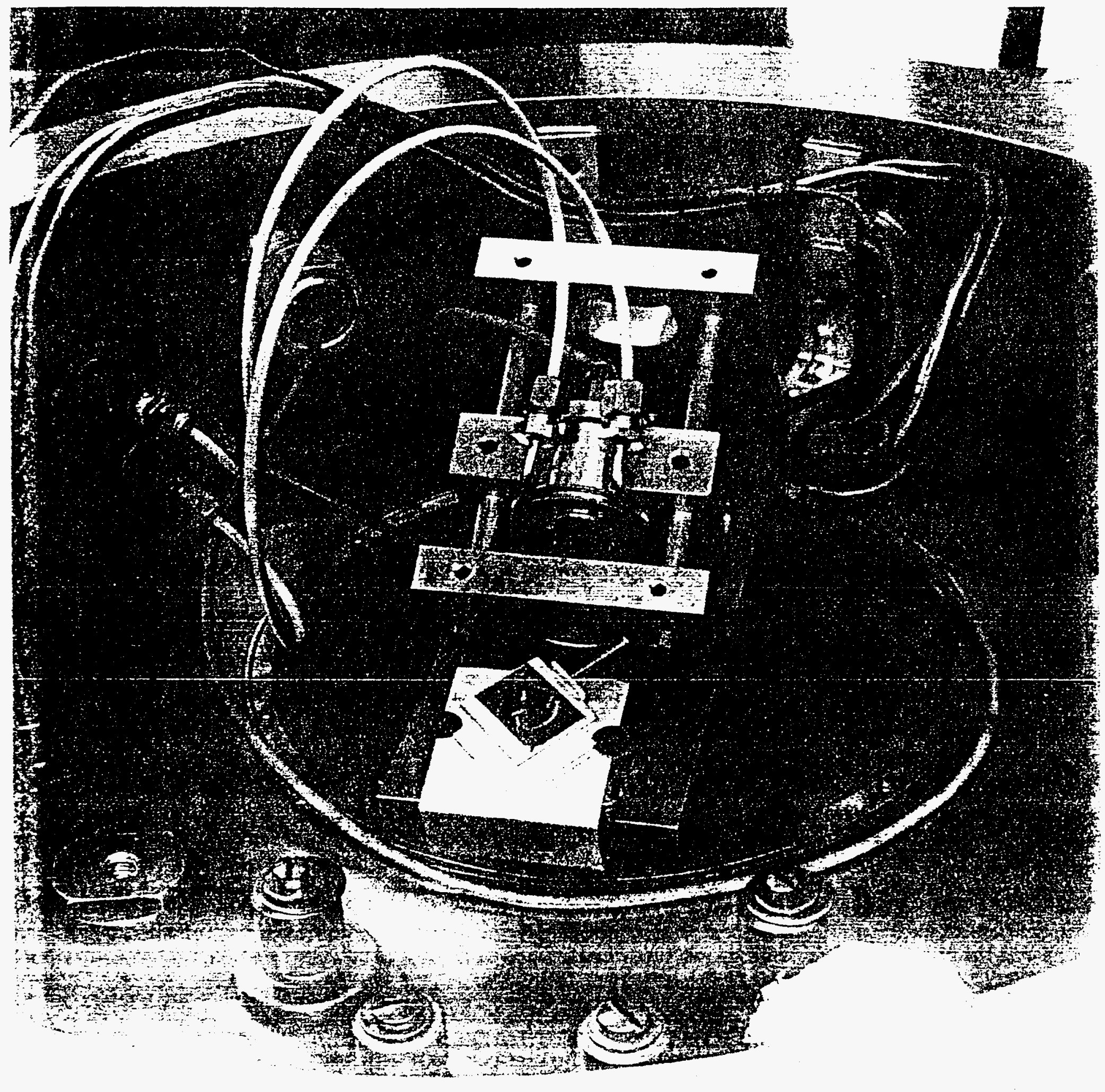


Au Foil Beam Profile

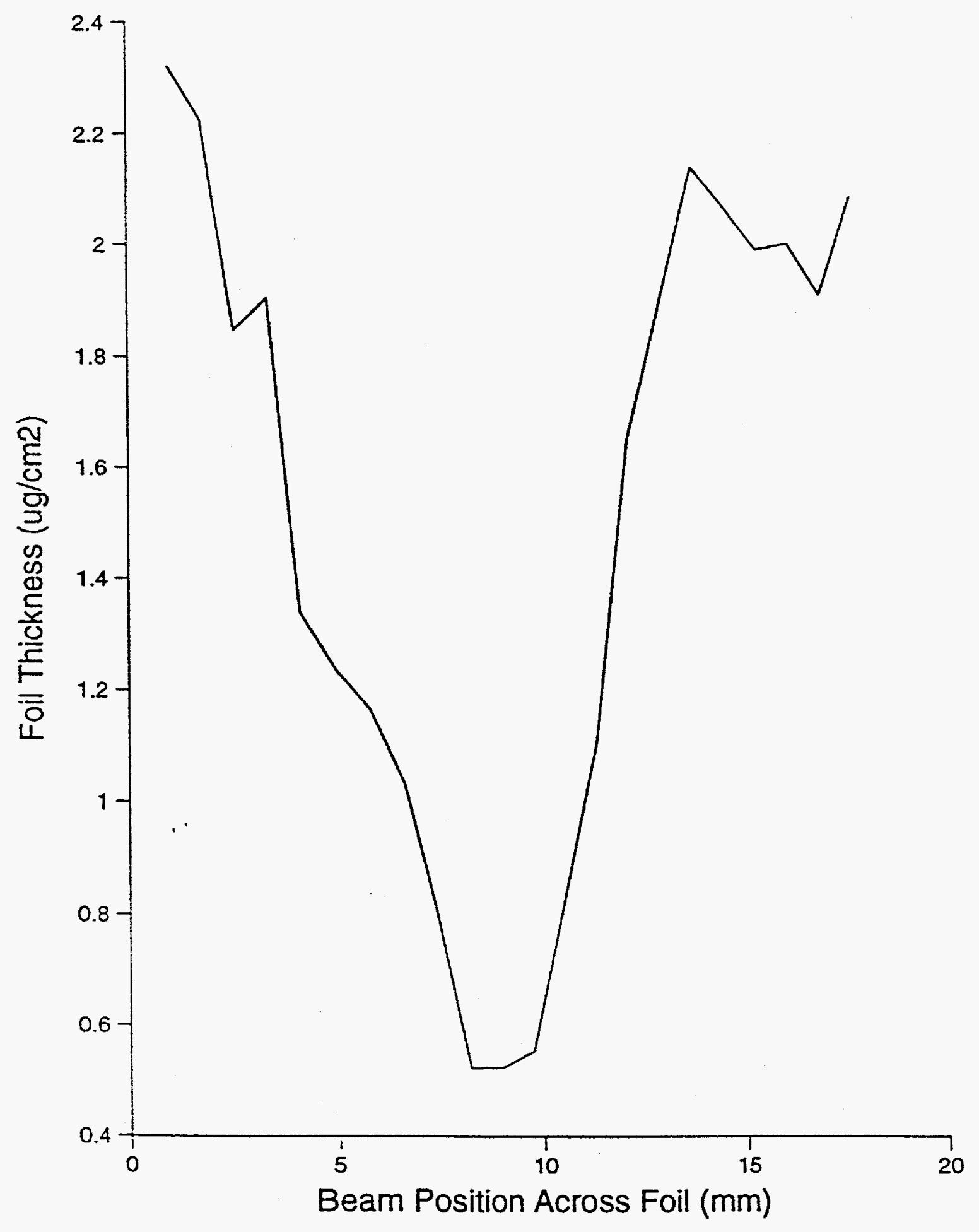

Fig. 5 
Ni Foil Beam Profile

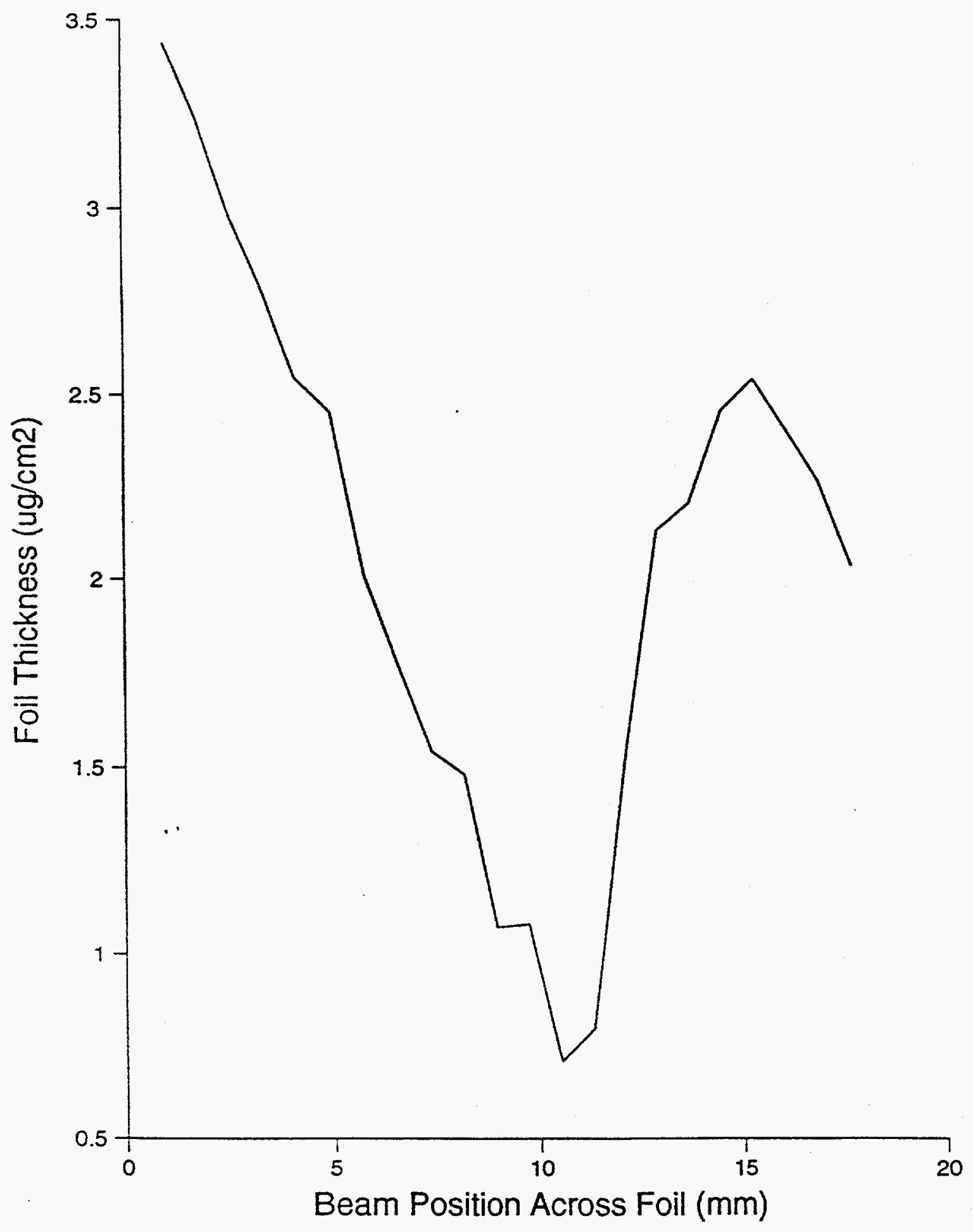

Fig. 6 


\section{Current vs. Voltage}

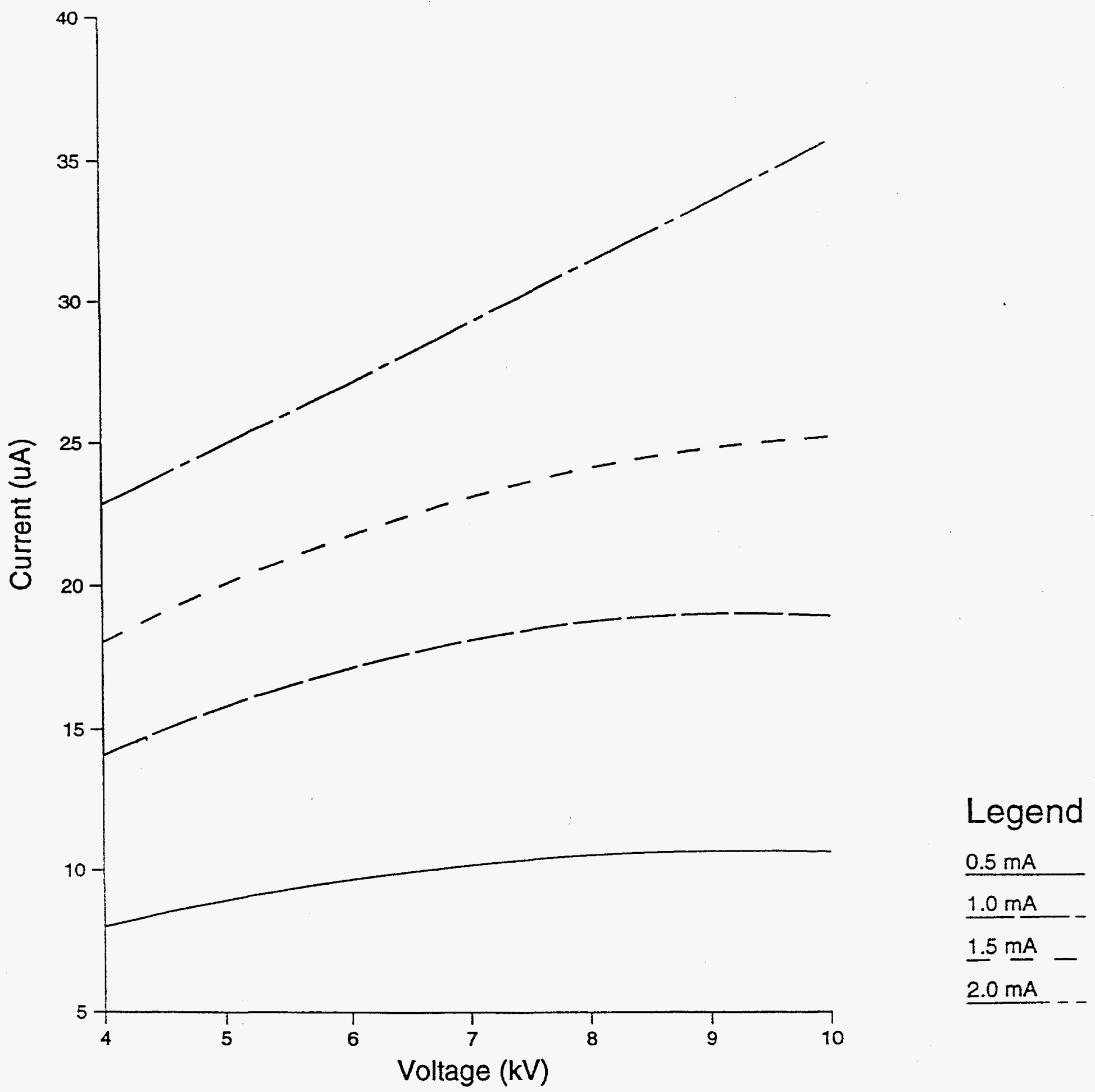

